NBER WORKING PAPERS SERIES

DESTABILIZING EFFECTS OF EXCHANGE-RATE ESCAPE CLAUSES

Maurice Obstfeld

Working Paper No. 3603

NATIONAL BUREAU OF ECONOMIC RESEARCH

1050 Massachusetts Avenue

Cambridge, MA 02138

January 1991

This paper was written while I was a visitor at the Department of Economics, Harvard University, and at the National Bureau of Economic Research. I thank both institutions for their hospitality, and the National science Foundation for financial support. Gian Maria Milesi-Ferretti made helpful comments. All errors are mine. This paper is part of NBER's research program in International studies. Any opinions expressed are those of the author and not those of the National Bureau of Economic Research. 
NBER Working Paper \#3603

January 1991

\section{DESTABILIZING EFFECTS OF EXCHANGE-RATE ESCAPE CLAUSES}

\section{ABSTRACT}

This paper studies the merits of policy rules with escape clauses, analyzing as an example fixed exchange-rate systems that allow member countries the freedom to realign in periods of stress. Motivating this example is the debate within the European Monetary system over how quickly to move from the current regime of national currencies, linked by pegged but adjustable exchange rates, to a single European currency.

The paper's main point is that while well-designed rules with escape clauses can raise society's welfare in principle, limited credibility makes it difficult for governments to implement such rules in practice. An EMS-type institution which presumably imposes a political cost on policymakers who realign - may lead to an optimal escape-clause equilibrium, but may just as well lead to alternative equilibria far inferior to an irrevocably fixed exchange rate. Countries can suffer periods in which no realignment occurs, yet unemployment, real wages, and ex post real interest rates remain persistently and suboptimally high.

Maurice obstfeld

Department of Economics

697 Evans Hall

University of California

at Berkeley

Berkeley, CA 94720 
Institutional restraints on monetary policy typically make special provision for exceptional circunstances. In times of economic crisis, a gold standard may be suspended, a monetary growth target breached, or an exchange rate realigned despite a previous international agreement fixing its level. Underlying such escape clauses is the idea that while institutional discipline is on the whole a good thing, social welfare may be improved if policymakers are granted discretion in the face of unusually severe shocks. ${ }^{1}$

This paper studies the merits of policy rules with escape clauses, analyzing as an example fixed exchange-rate systems that allow member countries the freedom to realign in periods of stress. Motivating this example is the debate within the European Monetary System over how quickly to move from the current regime of national currencies, 1 inked by pegged but adjustable exchange rates, to a single European currency.

The paper's main point is that while well-designed rules with escape clauses can raise welfare in principle, limited credibility makes it difficult for governments to implement them in practice. The problem is that an EMS-type institution - which presumably imposes a political cost on policymakers who realign - may lead to an optimal escape-clause equilibrium, but may just as well result in alternative equilibria far inferior to an irrevocably fixed exchange rate. ${ }^{2}$ Countries can suffer periods in which no

\footnotetext{
${ }^{1}$ Policy rules with escape clauses are examined by Flood and Isard (1989, 1990), Lohmann (1990), and Persson and Tabellini (1990). ${ }^{2}$ Cukierman (1990) shows how multiple equilibria can arise in a model with a costly devaluation option. In his model, however, exchange-rate changes play no stabilization role, so rigidly fixed
} 
realignment occurs, yet unemployment, real wages, and ex post real interest rates remain persistently and suboptimally high (probably a good description of Italy's recent experience). ${ }^{3}$

The paper is organized as follows. Section I sets out a model along the lines of Kydland and Prescott (1977) and Barro and Gordon (1983), in which a policymaker faces an incentive to raise employment above its natural rate through surprise currency depreciation. The policymaker has an informational advantage over the private sector, however, so policy interventions can play some stabilizing role. But leaving the policymaker free to stabilize entails a cost, as it imparts an inflationary bias to the economy. An optimal fixed exchange rate with realignment clauses, analyzed in section II, efficiently trades off higher mean inflation against more effective stabilization.

The policy rule described in section II is not time consistent. Section III describes how a fixed personal cost of

exchange rates are, by assumption, socially optimal. The model developed below has very different properties. Lewis (1989) mentions the possibility of multiple equilibria in a model where governments face fixed costs of entering into temporary international policy-coordination agreements. For a general discussion of the drawbacks of non-credible fixed exchange rates, including possible multiple equilibria, see Obstfeld (1985).

${ }^{3}$ Despite the stated desire for policy convergence within the EMS, Italy's 1989 unemployment rate stood at 12.0 percent (compared with a European Community average of 9.6); its unit labor costs increased in that year by 6.3 percent (compared with an EC average of 2.6 percent); and its annualized nominal three-month treasury bill rate was 12.7 percent (compared with three-month interbank rates of 9.3 percent in France and 7.1 percent in Germany). (See International Monetary Fund 1990.) Of course, Italy's large and growing public debt/GNP ratio must be reckoned as an additional source of credibility problems; and it may be part of the reason why Italy has suffered persistent inflation above the EC average. Calvo (1988) presents a theoretical analysis of multiple equilibria in a setting of public-debt devaluation. 
realigning, imposed on the policymaker by society, may induce him to implement the socially optimal escape-clause rule." But this is not the only possible outcome, as section IV shows. Even if socfety imposes the "correct" fixed cost, there may well be multiple equilibria, some leading to welfare levels far below the one achieved under an unconditionally fixed exchange rate.

Section $V$ summarizes the principal results and concludes.

\section{Commitment vs. Discretion in a Standard Model}

The analytical framework is a standard model of monetary policy choice, adapted to a small open economy.

On each date $t$, a policymaker sets the (log) exchange rate $e_{t}$ (the price of forefgn money in terms of domestic money). At the same time, the labor market determines an economy-wide nominal wage $w_{t+1}$ (also a log), at which workers agree to supply all the labor that firms demand on date $t+1$.

There is a single consumption good available; because its foreign-currency price is fixed, the exchange rate can be identified with the domestic price level. Labor-market equilibrium is assumed to require a constant expected real wage of 1 . Thus if $E\left\{e_{t} \mid I_{t-1}\right\}$ is the date $t-1$ conditional expectation of the date $t$ exchange rate, the wage negotiated on date $t-1$ for date $t$ is

\footnotetext{
"The general idea is related to Rogoff's (1985) argument that society may be able to increase its welfare, not by altering policymakers' incentives, but by choosing policymakers with preferences different from its own.
} 
(1) $w_{t}=E\left\{e_{t} \mid I_{t-1}\right\}$.

The information set $I_{t-1}$, which is common to the government and private sector, includes full and accurate data on the government's incentives and constraints.

Labor demand on date $t$ is inversely related to the real wage $w_{t}-e_{t}$ and an employment shock $u_{t}$ that is realized at the start of period $t$, before date $t$ labor demand is determined but too late to affect the prenegotiated nominal wage. The equation for date $t$ employment, $n_{t}$, is

(2) $n_{t}=n^{*}+\sqrt{\alpha}\left[\left(e_{t}-E\left\{e_{t} \mid I_{t-1}\right\}\right)-u_{t}-k\right]$.

In (2), $n^{*}$ should be thought of as the employment level targeted by the policymaker, while $k>0$ represents a fixed distortion in the economy that causes employment to deviate systematically from n*. (Of course, $k$ will be the source of the policymaker's credibility problem.) The shock $u_{t}$ is serially uncorrelated with zero mean.

The policymaker's preferences entail a tradeoff between employment levels closer to $n^{*}$ and inflation rates farther from his target of zero inflation. Specifically, on any date $t$ the policymaker would like to minimize the present discounted value of current and future expected period-by-period losses $L_{s}$,

(3) $\Lambda_{t}=E\left\{\sum_{s=t}^{\infty} \beta^{s-t} L_{s} \mid I_{t}\right\}$ 


$$
-E\left\{\sum_{s=t}^{\infty} \beta^{s-t}\left[\left(n_{s}-n^{*}\right)^{2}+\theta\left(e_{s}-e_{s-1}\right)^{2}\right] \mid I_{t}\right\} .
$$

Above, $e_{t}-e_{t-1}$ is domestic inflation, $0<\beta<1$, and $\theta>0$. The costs measured by (3) are assumed to be true social costs.

While labor markets pre-set $w_{t}$ in ignorance of the realized value of $u_{t}$, the policymaker is assumed to set the exchange rate after having observed the shock. In general the policymaker will want to use the exchange rate to offset some of the effect of $u_{t}$ on employment - for example, by unexpectedly depreciating the currency (raising $e_{t}$ above $e_{t-1}$ by an amount exceeding labor-market expectations) when $u_{t}$ turns out to be positive.

There are at least two distinct policymaking processes that might govern this management of the exchange rate. Under discretion authorities choose $e_{t}$ each period to maximize $\Lambda_{t}$, without regard to any policies that might have been announced in the past; In particular, discretionary policymaking takes past expectations as given. Since the model assumes no intertemporal linkages, ${ }^{5}$ the optimal policy under discretion is to maximize $L_{t}$, given $\mathrm{E}\left\{e_{t} \mid I_{t-1}\right\}$ as well as $u_{t}$. The exchange-rate change chosen in a discretionary regime therefore is

(4) $e_{t}-e_{t-1}=\lambda\left(E\left\{e_{t} \mid I_{t-1}\right\}-e_{t-1}\right\}+\lambda\left(k+u_{t}\right), \lambda=\frac{\alpha}{\alpha+\theta}$.

Under commitment, however, the authority binds itself ex ante for all $t \geq 0$ to an irrevocable exchange-rate rule of the form

\footnotetext{
"Note that "reputational" trigger-strategy equilibria are not
considered.
} 
(5)

$$
e_{t}-e_{t-1}=\epsilon\left(u_{t}, k\right)
$$

In what follows I will use the unconditional expected policy loss as a "Rawlsian" welfare criterion for ranking policy regimes. Under commitment, then, the authority solves the problem: Find a function $\epsilon\left(u_{t}, k\right)$ that minimizes the unconditional expectation $E\left\{\Lambda_{0}\right\}$ subject to $e_{t}-e_{t-1}=\epsilon\left(u_{t}, k\right)$ and $E\left\{e_{t} \mid I_{t-1}\right\}=e_{t-1}+$ $E\left\{\epsilon\left(u_{t}, k\right) \mid I_{t-1}\right\}$ for all $t \geq 0 .^{6} \quad$ (Note that the choice of policy rule is made in ignorance of the initial realization $u_{0}{ }^{7}$ ) In a linear-quadratic setting the optimal policy rule $\epsilon\left(u_{t}, k\right)$ is linear; it is easy to verify that the rule

$$
\epsilon\left(u_{t}, k\right)=e_{t}-e_{t-1}=\lambda u_{t}
$$

is optimal under commitment, where $\lambda \in[0,1]$ is defined in (4).

According to (6), the authority partially counters employment shocks through exchange-rate surprises, to a degree inversely related to the relative inflation-aversion coefficient $\theta / \alpha$, but it makes no attempt to offset the systematic employment distortion k. Mean inflation is zero under this commitment regime, and the (unconditional) expected policy loss is

\footnotetext{
${ }^{6}$ In fact, to obtain the commitment equilibrium it suffices that for any $t \geq 0$, the government be able to bind itself on date $t-1$ to the exchange-rate rule it will follow on date $t$.

${ }^{7}$ In reality a government choosing an optimal binding rule might do so knowing $u_{0}$ (or more generally, knowing something about the state of the economy over the near future). This knowledge would contaminate its choice of rule, with the degree of contamination depending inversely on the size of the discount factor $\beta$.
} 
(7) $E \Lambda^{C}=\alpha k^{2}+\gamma \sigma_{u}^{2}, \quad \gamma=(1-\lambda) \alpha$,

where $\sigma_{u}^{2}$ is the variance of $u$. [ In (7) and until further notice, $\beta$ - 0 is assumed for notational convenience. ${ }^{8}$ ]

Under discretion the exchange rate is set by (4). Rational expectations in the labor market ensure that in equilibrium

(8) $e_{t}-e_{t-1}=\frac{\lambda}{1-\lambda} k+\lambda u_{t}$,

implying an expected loss of

(9) $\mathrm{E} \Lambda^{D}=\boldsymbol{\gamma} \mathrm{E}\left(\frac{\lambda k}{1-\lambda}+k+u\right)^{2}-\mathrm{E} \Lambda^{C}+\theta \lambda^{2} k^{2} /(1-\lambda)^{2}$.

$E \Lambda^{D}$ exceeds $E \Lambda^{C}$ for a well-known reason: unless he can commit to zero mean inflation, the policymaker is free to try offseting the distortion $k$ through a surprise reduction in real wages. But the cost of this distortion, $\alpha k^{2}$ in (7), is irreducible. Since the labor market understands the authority's goals, equilibrium wages incorporate inflation expectations and thus rise at rate $\lambda k /(1-$ d) [see eq. (8)]. As a result, the additional policy loss implied by a discretionary regime is $\theta \lambda^{2} k^{2} /(1-\lambda)^{2}$.

One particular rule - suboptimal within the narrow confines of the present model - is a fixed exchange rate: $e_{t}=e_{t-1}$, for all $t$. The expected loss under this rule is ${ }^{8}$ To get general answers, divide the ex ante losses reported below
by $1-\beta$. 
(10) $E \Lambda^{F}-\alpha \mathrm{E}(k+u)^{2}-\alpha k^{2}+\alpha \sigma_{u}^{2}$.

A fixed rate allows for no policy response to the disturbance $u$, so $\mathrm{E}\left(\Lambda^{C}-\Lambda^{F}\right)=(\alpha-\gamma) \sigma_{u}^{2}$, the gain due to optimal stabilization. However, the fixed rate does avoid the secular inflation, at rate $\lambda k /(1-\lambda)$, implied by a discretionary regime. So in general, a comparison of $\mathrm{E \Lambda}^{F}$ (fixed rates) with $\mathrm{E} \Lambda^{D}$ (pure discretion) is ambiguous, depending in an obvious way on the values of $\theta / \alpha, k$, and $\sigma_{u}^{2}$

II. Nondiscretionary Escape Clauses

When the potential gains from stabilization are significant, a fixed exchange rate regime that allows discretion in exceptional circumstances may raise welfare compared to an unconditionally fixed rate. At the same time, a regime of pure discretion may be improved if some statutory limits are placed on the policymaker's exchange-rate choices. These observations give rise to the idea of policy rules embodying escape clauses.

This section studies nondiscretionary escape clauses: binding rules specifying when the exchange rate must be fixed, and when discretion is permissible. There is an obvious problem with such rules: How can society enforce them if policy commitments are not feasible? To address this problem, the next section will take up discretionary escape clauses, which are invoked when the policymaker chooses, but at a personal cost. The present section remains pertinent, though, as its results clarify the welfare implications 
of discretionary and nondiscretionary escape clauses alike. ${ }^{9}$

Consider a policymaker bound to the exchange-rate rule:

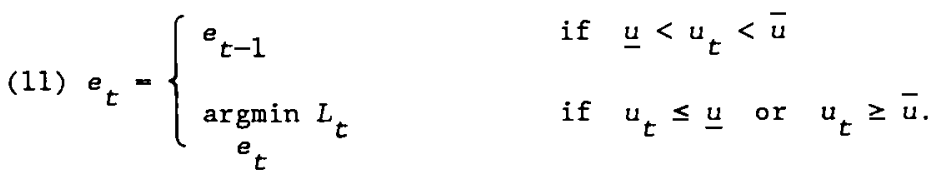

This rule instructs the policymaker to resort to discretion if $u_{t}$ assumes an extreme value, $i$.e., one that lies outside $(\underline{u}, \bar{u})$.

Expectations under rule (11) reflect the possibility of a reversion to discretion, and these expectations, in turn, affect the exchange rate chosen when discretion is indeed "on" [recal1 (4)]. Let $F(u)$ be the cumulative distribution function for the i.i.d. shock $u$, and define

$$
\underline{\pi} \equiv F(\underline{u})=\int_{-\infty}^{\underline{u}} d F(u), \quad \bar{\pi}-1-F(\vec{u})=\int_{\bar{u}}^{\infty} d F(u)
$$

The expected exchange rate under the assumed regime is

$$
\mathbf{E}\left(e_{t} \mid I_{t-1}\right)=\underline{\pi} \mathrm{E}\left\{e_{t} \mid u \leq \underline{u}\right\}+\bar{\pi} \mathrm{E}\left\{e_{t} \mid u \geq \bar{u}\right\}+(1-\underline{\pi}-\bar{\pi}) e_{t-1},
$$

which can be solved, using (4), for the equilibrium expectation

${ }^{9}$ It may seem artificial to consider binding escape-clause rules; after all, once binding rules are admitted to be feasible, many other rules would be better - for example, keep the exchange rate fixed within a set interval of $u$ values, but use the optimal rule (6) outside. The payoff, to repeat, is a benchmark for analyzing escape clauses that arise in reality and are enforced through sanctions applied to policymakers. As is discussed further below, imposing fixed social costs of exercising escape options would have little substantive impact on the analysis. 
(12) $\mathrm{E}\left(e_{t} \mid I_{t-1}\right)=e_{t-1}+\delta(\underline{u}, \bar{u})$,

where $\mathrm{e}^{10}$

(13) $\delta(\underline{u}, \bar{u})=\frac{\lambda[\underline{\pi}(k+E\{u \mid u \leq \underline{u}\})+\bar{\pi}(k+E\{u \mid u \geq \bar{u}\})]}{1-\lambda(\underline{\pi}+\bar{\pi})}$.

The unconditional expected loss is denoted by $\mathrm{E} \Lambda(\underline{u}, \bar{u})$, where

(14) $\mathrm{E} \Lambda(\underline{u}, \bar{u})=(1-\underline{\pi}-\bar{\pi}) \alpha \mathrm{E}\left\{[\delta(\underline{u}, \bar{u})+k+u]^{2} \mid u \in(\underline{u}, \bar{u})\right\}$

$$
+(\underline{\pi}+\bar{\pi}) \gamma E\left\{[\delta(\underline{u}, \bar{u})+k+u]^{2} \mid u \notin(\underline{u}, \bar{u})\right\} .
$$

Equation (14) is best understood by reference to the last section's results. Under both pure discretion and a fixed exchange rate, the policymaker's expected loss is proportional to $\mathrm{E}(\varphi+k+u)^{2}$, where $\varphi$ is the equilibrium expectation of depreciation $-\lambda k /(1-\lambda)$ under discretion, zero under a fixed rate [see equations (9) and (10), respectively]. With a fixed rate the proportionality constant is $\alpha$, while under discretion it is the smaller quantity $\gamma$, a reflection of the policymaker's ability to stabilize employment at the cost of secular expected inflation.

${ }^{10}$ Even if $\lambda=1$ (i.e., $\theta=0$ ), so that the policymaker puts no weight at all on inflation, the expected depreciation rate in (13) is finite as long as at least one threshold is finite. In contrast, equilibrium depreciation is infinite when $\lambda=1$ in the case of pure discretion [equation (8)]. 
The loss (14) averages over these two regimes in a particular way. In states of nature where the fixed rate holds steady, the expected loss is a times the corresponding conditional expectation of $(\varphi+k+u)^{2}$; in states where it does not, the expected loss is $\gamma$ times the conditional expectation of $(\varphi+k+u)^{2}$ corresponding to discretion. Overall expected loss is the appropriate probability-weighted average. The trend expected depreciation rate $\varphi=\delta(\underline{u}, \bar{u})$ is constant across realizations of $u$ and leads to a "peso problem": under fixed rates there is the possibility of a parity change, while under discretionary exchange-rate management there is the possibility of a return to fixed rates. ${ }^{11}$ In general, $\delta(\underline{u}, \bar{u})$ may be positive or negative. If negative, it may exceed $k$ in absolute value; while if positive (as section IV shows), it may even exceed the trend depreciation rate under pure discretion. Naturally, the model implies pure discretion as $\bar{u}-\underline{u} \rightarrow 0$, a pure fixed rate as $\bar{u}$ and $-\underline{u} \rightarrow \infty$.

Nondiscretionary escape clauses that strictly dominate both pure discretion and an irrevocably fixed exchange rate often can be designed. ${ }^{12}$ It is thus meaningful to examine interior solutions for the optimal escape-clause rule. Let $f(u)$ be the derivative of the distribution function $F(u)$. Differentiation of $E \Lambda(\underline{u}, \bar{u})$

${ }^{11}$ The expectation $\varphi$ is independent of $u$ because that shock is 1.i.d. Allowing serial correlation in $u$ would complicate the results (and arguably add to their descriptive realism), but wouldn't alter any fundamental insights. For example, for given escape thresholds, positive serial correlation in $u$ would make wages an increasing function of $u$. Furthermore, the optimal thresholds (to be described in a moment) generally would depend on the previous period's shock realization.

${ }^{12}$ See Persson and Tabellini (1990) for a good discussion of a special case. By construction, no such rule strictly dominates the optimal rule (6). 
[equation (14)] with respect to the thresholds $\underline{u}$ and $\bar{u}$ yields first-order conditions for an interior optimum:

(15a) $\mathrm{E} \Lambda_{1}(\underline{u}, \bar{u})=-(\alpha-\gamma)[\delta(\underline{u}, \bar{u})+k+\underline{u}]^{2} f(\underline{u})$

$$
\begin{aligned}
& +2 \alpha \int_{u \in(\underline{u}, \bar{u})} \delta_{1}(\underline{u}, \bar{u})[\delta(\underline{u}, \bar{u})+k+u] d F(u) \\
& +2 \gamma \int_{u \notin(\underline{u}, \bar{u})} \delta_{1}(\underline{u}, \bar{u})[\delta(\underline{u}, \bar{u})+k+u] d F(u)=0,
\end{aligned}
$$

(15b) $E \Lambda_{2}(\underline{u}, \bar{u})=(\alpha-\gamma)[\delta(\underline{u}, \bar{u})+k+\bar{u}]^{2} f(\bar{u})$

$$
\begin{aligned}
& +2 \alpha \int_{u \in(\underline{u}, \bar{u})} \delta_{2}(\underline{u}, \bar{u})[\delta(\underline{u}, \bar{u})+k+u] d F(u) \\
& +2 \gamma \int_{u \notin(\underline{u}, \bar{u})} \delta_{2}(\underline{u}, \bar{u})[\delta(\underline{u}, \bar{u})+k+u] d F(u)=0 .
\end{aligned}
$$

These conditions actually are not too hard to interpret. A small increase in $\underline{u}$, for example, has two effects. Given market expectations, it marginally increases the range of shocks over which the authority can exercise employment-stabilizing policy, thereby reducing expected losses by $(\alpha-\gamma)[\delta(\underline{u}, \bar{u})+k+\underline{u}]^{2} f(\underline{u})$. But it also affects equilibrium expectations across all states of nature, shifting the entire functional relationship between $u$ and L. The incremental expectations effect, the sum of the two integral expressions in (15a), must just cancel the incremental 
stabilization gain at an optimum (so in particular the former effect must increase expected losses). A similar characterization applies to $(15 b)$. $^{13}$

Attaining the optimum described by (15) is problematic, because the optimization assumes that a a binding rule governs the circumstances in which discretion is permitted. In effect, the policymaker, like Saint-Exupéry's Little Prince, is "commanded to do exactly what he wants to do," but only in certain states of the world. This policy rule is clearly time inconsistent: absent a commitment mechanism, the policymaker will always do what he wants to do, namely, exercise full discretion.

One way to impose a nonzero probability that a steady exchange rate is optimal ex post is to posit a fixed social cost $\chi$ of currency realignment, over and above the costs captured by the term $\theta\left(e_{t}-e_{t-1}\right)^{2}$ in (3). Even under discretion, such a cost may induce the policymaker to keep $e$ fixed over a range of $u$ realizations. The time-inconsistency problem remains, however, because the policymaker's discretionary behavior generally will not minimize the ex ante social loss $E \Lambda-(\underline{\pi}+\bar{\pi}) \chi$.

A fixed private cost of realignment, imposed on the policymaker only, could reduce the divergence between discretionary behavior and the ex ante optimal escape-clause rule. For example, a government might lose political capital if it has to alter the exchange rate. When the authority conducts a

${ }^{13}$ Notice that when $u$ is distributed symmetrically around zero, the optimal bounds are not symmetric: $\bar{u}<-\underline{u}$ because $k>0$. Even symmetric bounds, such as those analyzed by Persson and Tabellini (1990), may raise welfare compared with discretion or fixed rates. 
cost-benefit analysis of realignment each period, however, its decision to exercise the escape clause is discretionary. The next section analyzes escape clauses triggered by discretion rather than by a rule.

\section{Discretionary Escape Clauses}

A well-designed escape clause is potentially welfare-improving, but can fixed political costs of currency realignments induce policymakers to implement it under discretion? The answer is of particular interest in light of the EMS, which is often viewed as an institution that imposes such costs. In this section $I$ argue that there can be no general presumption that a discretionary escape clause will reproduce the social optimum.

Assume that the policymaker faces a cost $\underline{c}$ of revaluing the currency (lowering $e$ ) and a cost $\bar{c}$ of devaluing (raising $e$ ). In a discretionary regime the authority takes the market's expected devaluation rate, $\varphi$, as given; accordingly ex post period loss is

$$
L^{F}(\varphi, u)=\alpha(\varphi+k+u)^{2}
$$

if the fixed exchange rate is maintained, given $u$, and is

(17) $L^{D}(\varphi, u) \equiv \gamma(\varphi+k+u)^{2}$

if the choice is to realign. ${ }^{14}$

\footnotetext{
${ }^{14}$ The formulation here assumes that realignment carries no extra fixed social costs. These could easily be incorporated without
} 
Since the future is unaffected by decisions made today, the policymaker's sole concern is the short-run social-cost differential, $L^{F}-L^{D}$, net of the fixed cost of any parity adjustment. The policymaker's optimal decision rule is simple: it is to devalue the currency for $u \geq \bar{u}$, where $\bar{u}$ is the solution to

(18a) $L^{F}(\varphi, \bar{u})-L^{D}(\varphi, \bar{u})=(\alpha-\gamma)(\varphi+k+\bar{u})^{2}-\bar{c}$;

and to revalue for $u \leq \underline{u}$, where $\underline{u}$ is the solution to

$$
L^{F}(\varphi, \underline{u})-L^{D}(\varphi, \underline{u})-(\alpha-\gamma)(\varphi+k+\underline{u})^{2}-\underline{c} .
$$

Figure $I$ illustrates how $\underline{\underline{u}}$ and $\bar{u}$ are determined.

The relationships shown in the figure suggest a way of implementing the socially optimal escape-clause rule. Let $\underline{u}$ and $\bar{u}$ be the optimal switch points characterized by (15); then set $\underline{c}$ and $\bar{c}$ at the levels

$$
\underline{c}=(\alpha-\gamma)[\delta(\underline{u}, \bar{u})+k+\underline{u}]^{2}, \quad \bar{c}=(\alpha-\gamma)[\delta(\underline{u}, \bar{u})+k+\bar{u}]^{2} .
$$

Faced with market depreciation expectations $\delta(\underline{u}, \bar{u})$, the authority will pick the optimal boundaries $\underline{u}$ and $\vec{u}$ if the fixed realignment costs specified in (19) are imposed [compare (18) with (19)].

There is one problem with this scheme. It works perfectly

changing the analysis below. The key point about such costs is the one made at the end of the last section: fixed social costs alone cannot induce the policymaker to implement the ex ante optimal rule. An incentive structure that penalizes the policymaker without penalizing the rest of society - for example, a saiary cut that accrues to the government budget - is indispensable. 


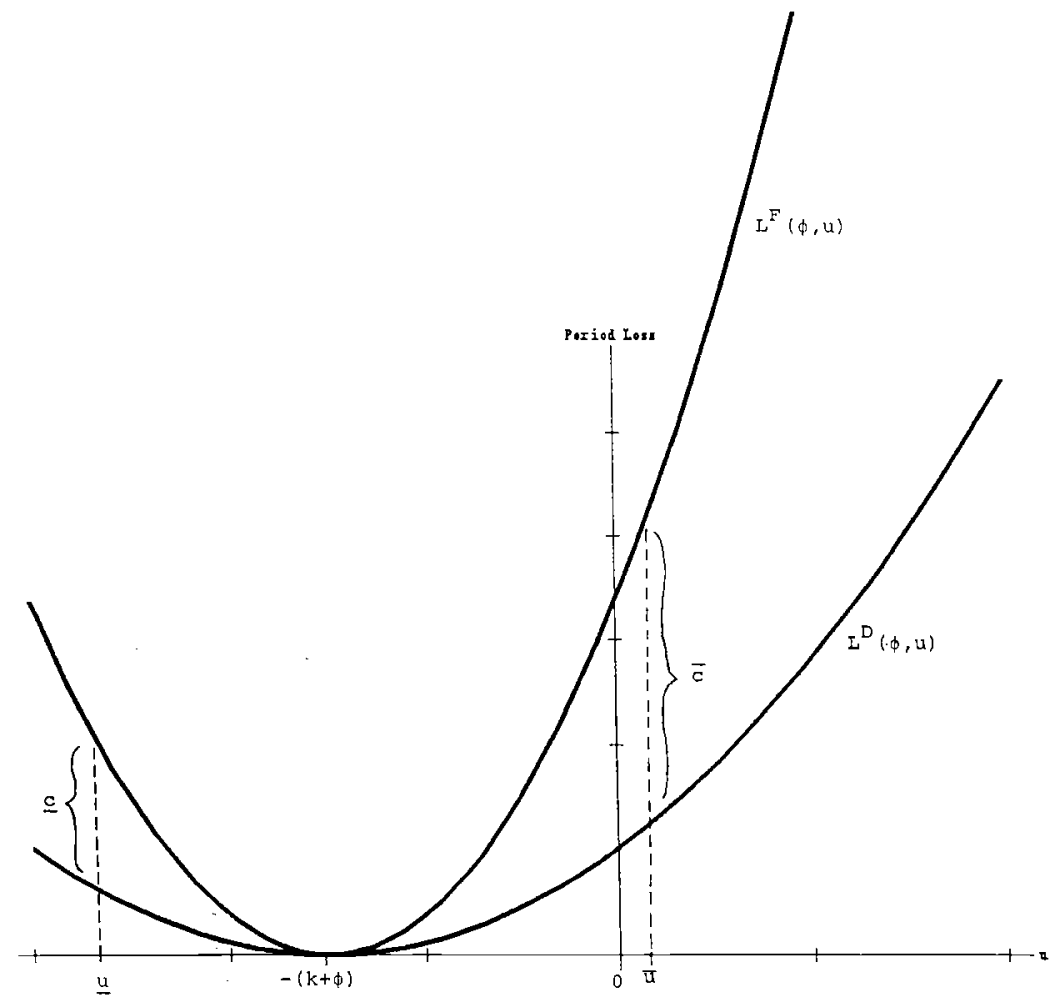
Figure 1: Determination of realignment thresholds
under discretion 
well if the market expects the currency to deprectate at rate $\varphi=$ $\delta(\underline{u}, \bar{u})$ on average. But there may be no way to ensure that this is the market's expectation. As (18) shows, changing $\varphi$ to $\varphi^{\prime}$, say, will lead to different switch points, $\underline{u}^{\prime}$ and $\bar{u}^{\prime}$, even if the fixed realignment costs do not change; and an additional rationalexpectations equilibrium will arise whenever $\varphi^{\prime}=\delta\left(\underline{u}^{\prime}, \bar{u}^{\prime}\right)$. In general we would expect such an equilibrium to produce a strictly lower social welfare level than the one described by (15). In particular, an equilibrium with a rate of expected depreciation greater than under the optimal rule will also lead to a higher real wage and thus to higher unemployment when the escape clause is not exercised.

Why should multiple equilibria arise at all? The answer lies in the policymaker's inability, under a discretionary regime, to forswear credibly the accommodation of expected depreciation. A rise in expected depreciation on date $t-1$, other things the same, can push the economy farther from full employment on date $t$; and as (4) shows, the policymaker will create some date-t inflation to mitigate this employment effect, with the propensity to accommodate measured by $\lambda$. Under a discretionary escape clause, different expected switch points imply different exchange rate expectations. An accommodative (high $\lambda$ ) policymaker may alter his preferred switch point so as to ratify a change in expectations.

One might hope to be more successful at implementing an optimal escape-clause rule through more complicated incentive structures - for example, schemes that make the policymaker's penalty depend on the size of a realignment. Such schemes are not considered below. As the subsequent analysis will reveal, state- 
dependent penalties would help only if they could be designed with very detailed knowledge of the economy's structure. Sufficiently detailed knowledge is not available in practice, and clearly does not inform the sanctions that real-world policymakers face.

Even for fixed realigment costs, the multiplicity of equilibria, and their welfare properties, depend in a complicated way on the distribution function $F(u)$. For this reason, I now take a detailed look at a specific, but empirically plausible, example.

\section{Multiple Equilibria: An Example}

To simplify the analysis, I assume that the fixed cost of revaluation is big enough that only large positive realizations of u occasion discretion, in which case a devaluation occurs. This assumption leads to a fairly realistic description of the positions of several countries: no one currently places great weight on the possibility that the Italian lira will be revalued against the deutschemark. Also, having to solve only for a single equilibrium boundary, $\bar{u}$, simplifies the algebra considerably.

A devaluation option of this sort imparts a definite inflation bias to the regime; a welfare gain over pure discretion can arise only when the mean inflation bias falls as a result of the limits on the exchange rate's flexibility. On the negative side, the escape clause makes employment more variable compared with a free float: in non-devaluation states, employment is below the level that would prevail under discretion, while in devaluation states, it is higher. Because employment is less variable than under a rigidly fixed exchange rate, however, a 
mixed regime may - but need not - dominate either polar regime.

In line with the simplifying assumption that only devaluation is possible, define $\delta(\bar{u})$ as the expected depreciation rate when the authority holds the exchange rate fixed for $u<\bar{u}$, but devalues otherwise:

$$
\delta(\bar{u})=\lim _{\underline{u} \rightarrow-\infty} \delta(\underline{u}, \bar{u})
$$

[see equation (13)]. All the formulas derived above can be extended to the present, simpler, setting by replacing $\delta(\underline{u}, \bar{u})$ with $\delta(\bar{u})$. In particular, (15b), so modified, describes a fixed rate with an interior optimal devaluation option. ${ }^{15}$

The specific distribution assumed for $u$ has the tent-shaped density function:

$$
f(u)= \begin{cases}(\mu-|u|) / \mu^{2} & \text { for } u \in[-\mu, \mu] \\ 0 & \text { for } u \notin[-\mu, \mu] .\end{cases}
$$

Under this distribution, $\sigma_{u}^{2}=\mu^{2} / 6$.

Direct calculation yields the inflation bias of the regime,

(20a) $\delta(\bar{u})=\frac{\lambda \bar{\pi}[k+E\{u \mid u \geq \bar{u}\})}{1-\lambda \bar{\pi}}$,

${ }^{15}$ of course, there is no general presumption of an interior optimum. In the example of this section, $\bar{u}=-\mu$ is always a local (and sometimes a global) minimum of the expected loss function. 
(20b) $\bar{\pi}- \begin{cases}1-(\mu+\bar{u})^{2} / 2 \mu^{2} & \text { for } \bar{u} \in[-\mu, 0] \\ (\mu-\bar{u})^{2} / 2 \mu^{2} & \text { for } \bar{u} \in(0, \mu],\end{cases}$

(20c) $E\{u \mid u>\bar{u}\}-\left(\mu^{3}+2|\bar{u}|^{3}-3 \mu \bar{u}^{2}\right) / 6 \bar{\pi} \mu^{2}$.

Naturally, $\delta(\bar{u}) \rightarrow 0$ as $\bar{u} \rightarrow \mu$ (and the escape option disappears); while $\delta(\bar{u}) \rightarrow \lambda k /(1-\lambda)$ as $\bar{u} \rightarrow-\mu$ (in which case discretion prevails with probability one).

Before even searching for equilibria, it is illuminating to ask how expected depreciation varies with the switch point $\bar{u}$. Figures $2 \mathrm{a}$ and $2 \mathrm{~b}$ illustrate the parameter-dependent answer. In figure 2 a expected depreciation, $\delta(\bar{u})$, declines monotonically over $[-\mu, \mu]$; in figure $2 b$, however, it rises initially before bending downward and falling to zero.

The second pattern occurs whenever $k /(1-\lambda)<\mu$. In this second case, there exist values of $u$ negative enough - that is, positive employment shocks large enough - to cause currency appreciation under pure discretion [see (4)]. Under the escape clause, however, the exchange rate remains fixed in the face of such shocks; the resulting truncation of the exchange rate's distribution can raise expected inflation under the adjustable peg above its free-float level. (Clearly such a situation is inferior to discretion: mean inflation is raised at the same time that the authority's ability to offset employment shocks is curtailed.)

Now consider equilibria. Equation (18a) describes how the 


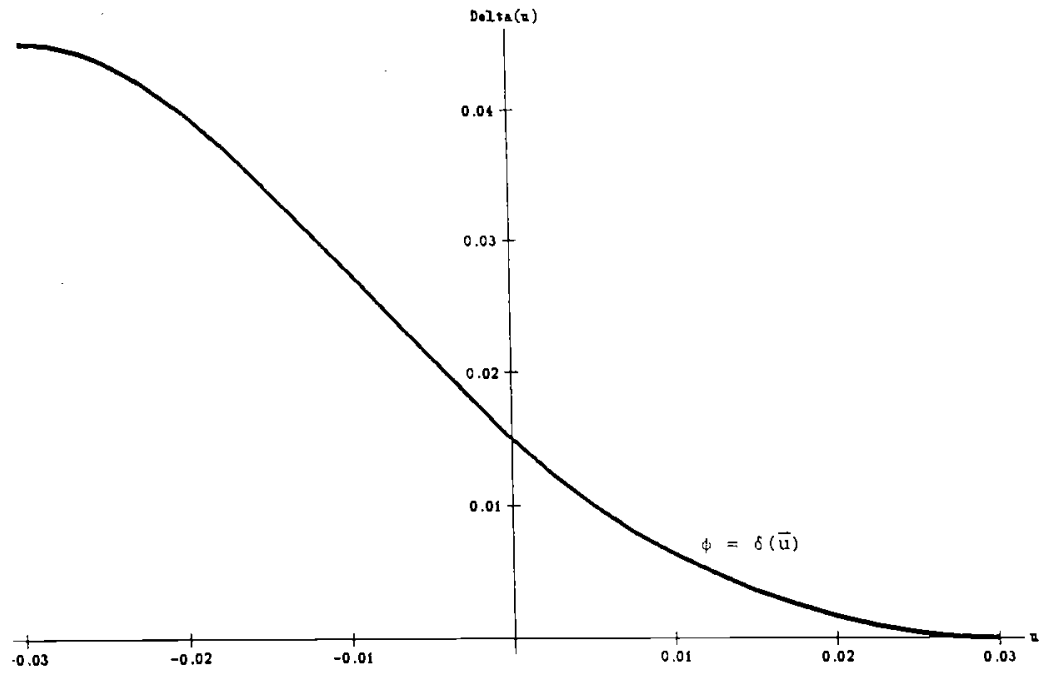

Figure 2a: Expected depreciation as a function of $\bar{u}$ 


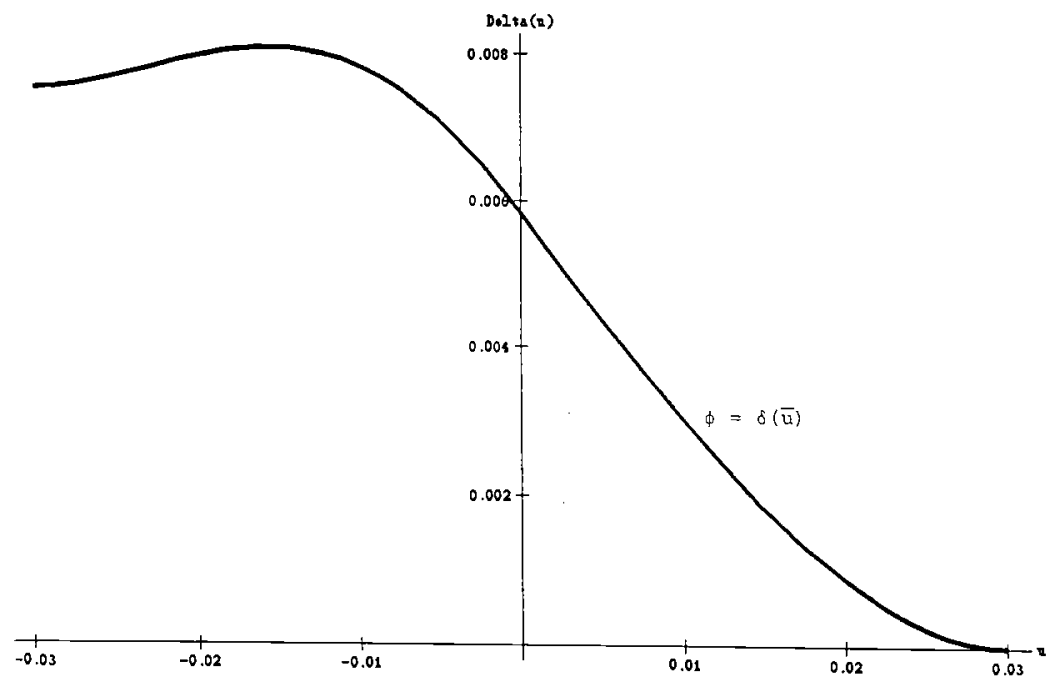

Figure 2b: Expected depreciation as a function of $\bar{u}$ 
policymaker will choose a switch point $\bar{u}$ given expected depreciation $\varphi$; equilibrium requires, in addition, that $\varphi=\delta(\bar{u})$. Given the fixed $\cos t \vec{c}$, the set of equilibrium switch points are the solutions to the equation in $\bar{u}$,

$$
L^{F}[\delta(\bar{u}), \bar{u}]-L^{D}[\delta(\bar{u}), \bar{u}]=(\alpha-\gamma)[\delta(\bar{u})+k+\bar{u}]^{2}=\bar{c}
$$

More simply, equilibria are described by values of $\bar{u}$ that solve ${ }^{16}$

(21) $\delta(\bar{u})+k+\bar{u}=\Gamma(\bar{u})-\sqrt{\bar{c} /(\alpha-\gamma)}=\kappa$.

Alternative equilibria are most easily studied by graphing the function $\Gamma(u)$ defined by $(20)$ and (21). Several different shapes for this function emerge as the parameters $k$ and $\lambda$ - which respectively measure the severity of the time-inconsistency problem and the willingness to accommodate - are varied. It will be assumed in the four examples below that $\alpha=3$ and $\mu=0.03$.

1. Equilibrium may be unique. Consider an economy with a relatively small time-inconsistency problem $(k=0.0075)$ whose policymaker is fairly averse to accommodation $(\lambda=0.5)$. Figure 3 shows the expected loss EA(u) implied by the different possible switch points $u \in[-0.03,0.03]$ (upper panel), along with the $\Gamma(u)$ function that arises in this case (lower panel).

\footnotetext{
${ }^{16}$ What about solutions to $\delta(\bar{u})+k+\bar{u}=-\sqrt{\bar{c} /(\alpha-\gamma)}=-\kappa$, which also satisfy the last equation? These define smallest positive employment shocks such that the authority would be willing to revalue - not devalue - at cost $\bar{c}$. Such solutions can be disregarded because revaluations have been ruled out.
} 


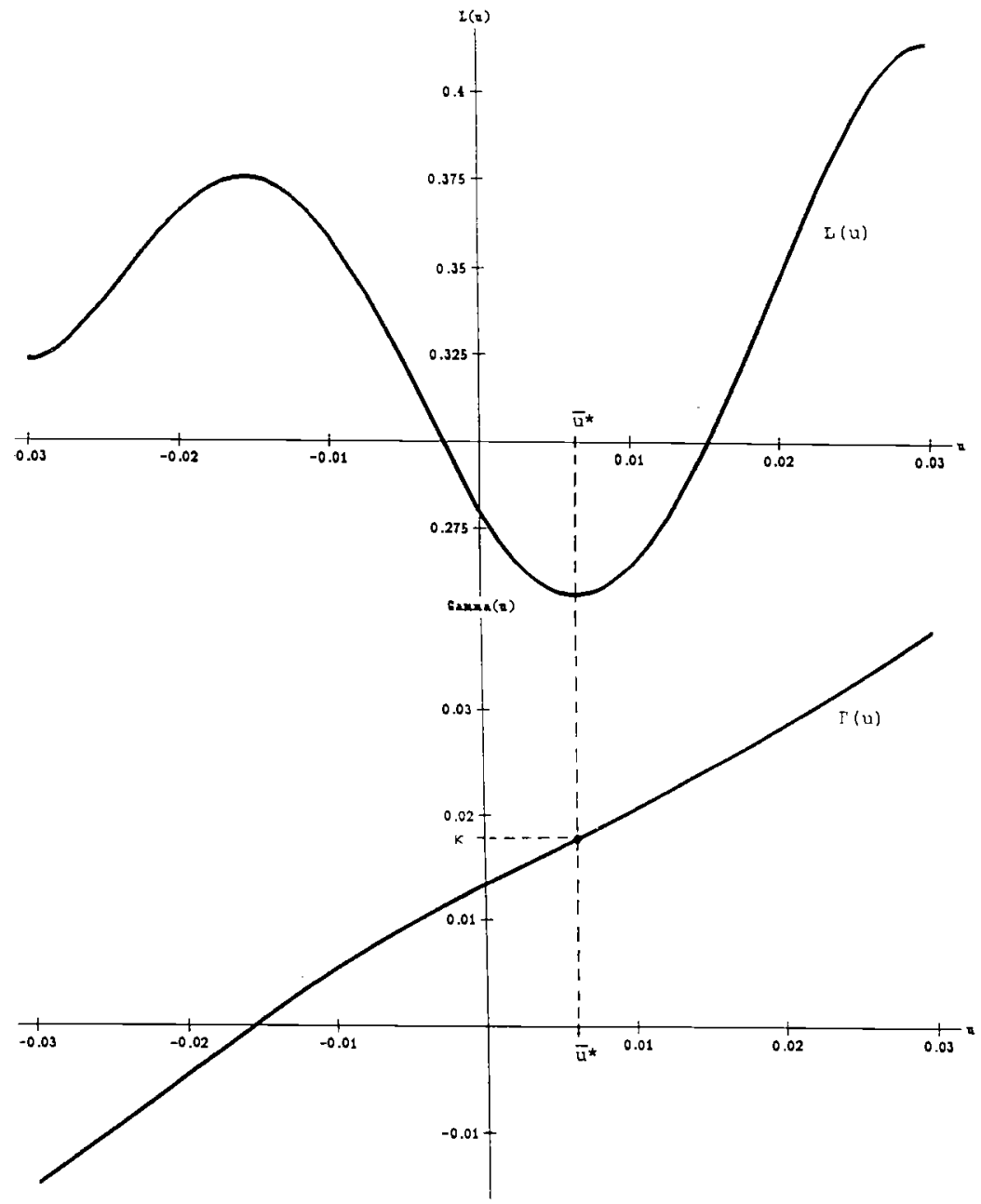

Figure 3: Unique equilibrium with $\lambda=0.5, k=0.0075$ 
The upper panel's vertical axis measures losses in terms of a concrete metric. Given an employment distortion of size $k$ and a disturbance variance of $\sigma_{u}^{2}$, the lowest possible expected loss under the assumed information structure is $E \Lambda^{C}=\alpha k^{2}+\gamma \sigma_{u}^{2}$, which is achieved if commitment is possible [equation (7)]. I measure loss under any other regime by imagining an authority endowed with a costless commitment mechanism, and computing the percent increase in the standard deviation $\sigma_{u}$ that would raise his loss to the level sustained in the alternative regime. If the alternative regime is one with a devaluation option starting at $\vec{u}$, this loss measure is

$$
L(\bar{u})=\sqrt{\left(E \Lambda(\bar{u})-\alpha k^{2}\right) / \gamma \sigma_{u}^{2}} .
$$

In figure 3 the optimal switch point $\bar{u}^{*}$ is .0063 (implying a devaluation probability of 0.312 ). The policy loss at this point is 25.6 percent - meaning that the cost of this regime relative to the optimal regime is equivalent to allowing commitment, but increasing the standard deviation $\sigma_{u}$ from 0.0122 to 0.0154 .

The optimal devaluation rule is an improvement over both pure discretion $(\bar{u}--0.03$, with an associated cost of 0.323$)$ and an unconditional peg $(\bar{u}=0.03$, with a cost of 0.414$)$. Note that a free float dominates a rigidly fixed exchange rate. The example shows that in principle, some limits to exchange-rate flexibility can raise welfare, even though a rigidly fixed rate would not.

Can the optimal switch point be delegated under discretion by imposing the appropriate devaluation cost on the policymaker? In 
this example it can. As the lower panel of figure 3 shows, the $\Gamma(u)$ function is strictly increasing: setting $\kappa-\Gamma(\bar{u} *)$ [as equation (21) directs] induces the policymaker to devalue when, and only when, $u \geq \bar{u}^{*}$. Expected depreciation in this regime is $\varphi^{*}$ $=0.4$ percent per period (compared with 0.75 percent under a free float, and zero under a fixed rate). And equilibrium is unique: given $\kappa$, no expected depreciation rate $\varphi^{\prime}$ other than 0.4 percent can lead the policymaker to a switch point $\bar{u}^{\prime}$ where $\varphi^{\prime}=\delta\left(\bar{u}^{\prime}\right)$.

2. There may be two equilibria, both of which dominate a pure fixed rate. To obtain this case, imagine that all parameters are as in the previous example, except that the policymaker is much more accommodative: now, $\lambda=0.9$.

Figure 4 again graphs the relevant functions. The top panel Indicates the optimal switch point $\bar{u} *=0.0049$ (which is below the last example's boundary at $u=0.0063$, in line with the present authority's greater interest in stabilization). The loss implied by this regime is 1.365 , lower than under a fixed rate $[\mathrm{L}(0.03)=$ $2.162]$ or pure discretion $[L(-0.03)=4.895]$. The discretionary regime does so poorly because it implies inflation at 6.75 percent per period; under the optimal devaluation rule, however, expected inflation is only 0.96 percent per period.

Now, however, the optimal escape-clause rule cannot always be replicated by imposing a well-chosen cost on a discretionary policymaker. As the lower part of figure 4 shows, just setting $\kappa=$ $\Gamma\left(\bar{u}^{*}\right)$ results in two equilibria. At the switch point $\bar{u}^{\prime}$. -0.00061 , expected depreciation is $\varphi^{\prime}=\delta\left(\bar{u}^{\prime}\right)=1.5$ percent $>\varphi^{*}=$ $\delta(\bar{u} *)=0.96$ percent; and since $\Gamma\left(\bar{u}^{\prime}\right)=\kappa$, it is just worthwhile 


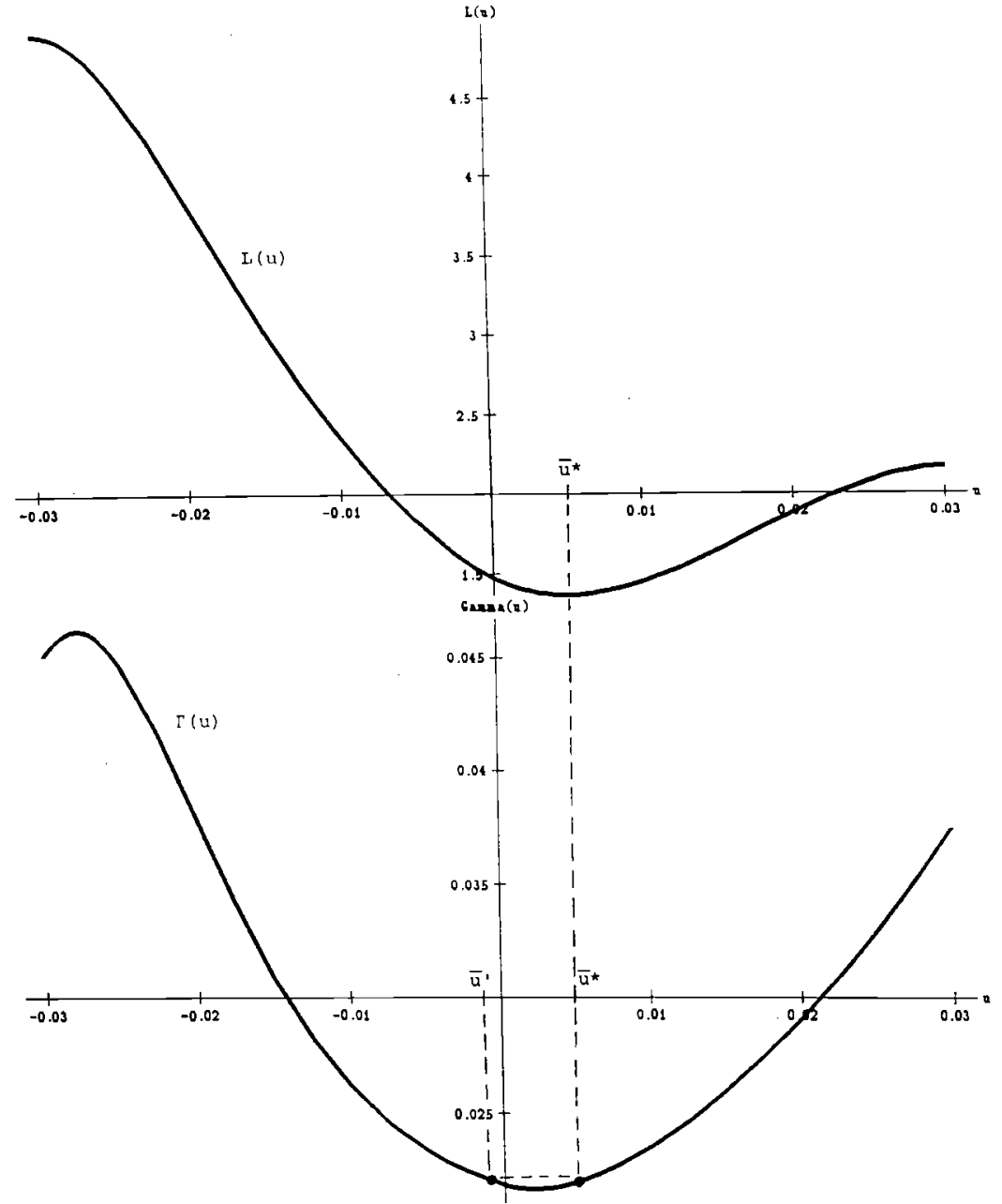

Figure 4: Multiple equilibria with $\lambda=0.9, k=0.0075$ 
for the policymaker to devalue at this boundary. If markets believe $\overline{u^{\prime}}$ is the devaluation threshold, the policymaker will ratify that belief rather than tolerate excessive ex post real wages and unemployment.

Real wages in this second equilibrium are higher than in the first in non-devaluation states; accordingly, unemployment is higher whenever the exchange rate remains fixed. In devaluation states, too, the real wage turns out to be higher, and employment lower, in the second equilibrium. ${ }^{17}$ This is true despite the fact that when currency depreciation does occur it is sharper in the second equilibrium, because nominal wages are further out of line with the authority's employment goals. A more detailed model would predict higher ex post real interest rates in non-devaluation states at the high-depreciation equilibrium, and a real exchange rate less competitive in either state.

In this example the cost of being at the second equilibrium is not too severe: the social cost is 1.504 , compared with 1.365 at the optimum and 2.162 under a fixed rate. Because the authority places so heavy a weight on reducing employment fluctuations, the greater scope for stabilization at $\bar{u}^{\prime}$ offsets to a large degree the higher expected inflation there, leaving the second equilibrium still preferable to a pure fixed rate.

But remember the assumption that $k=0.0075$ : the time-inconsistency problem is not too serious. As the next example shows, increasing the distortion $k$ can reverse these welfare rankings.

\footnotetext{
${ }^{17}$ Because devaluation is more likely in the second equilibrium, however, the expected wage and expected employment are the same
} 
3. There may be two equilibria, one of which is worse than a fixed rate. Now set $k=0.015$. The optimal switch point, $\bar{u}^{*}=$ 0.0144 , is considerably above that in the last case (greater discretion now is more dangerous), and it results in a lower expected depreciation rate of 0.48 percent per period. (See figure 5). The probability of devaluation is only 0.135. Attempting to decentralize this optimum, however, may result in the equilibrium switch point $\bar{u}^{\prime}=0.00167$, with expected depreciation at 1.75 percent per period and a 0.446 devaluation probability.

The optimal devaluation rule implies a loss of $L\left(\bar{u}^{*}\right)-1.902$ compared with a greater loss of 2.162 under a fixed exchange rate. But the alternative equilibrium is worse than either: $L\left(\bar{u}^{\prime}\right)-$ 2.653. If there is a substantial risk of ending up at this second equilibrium, it might be best to go for an irrevocably fixed exchange rate - perhaps by confronting the policymaker with a prohibitively high cost of devaluation.

One might think that the problem just described arises because a serious distortion is combined with a very high propensity to accommodate; reducing the latter might show the escape-clause idea in a better light. My fourth and last example therefore considers a policymaker who faces the same distortion level as in the present example $(k=0.015)$, but who is somewhat less accommodative. The answer is quite surprising.

4. There may be three equilibria, two of which are very bad compared with the best one or with a fixed rate. Now reduce $\lambda$ from 0.9 to 0.075 . The best equilibrium would be at $\bar{u}^{*}=0.0145$ (figure 6), with a loss of $L\left(\bar{u}^{*}\right)=0.867$, expected depreciation of $\varphi^{*}=$ 


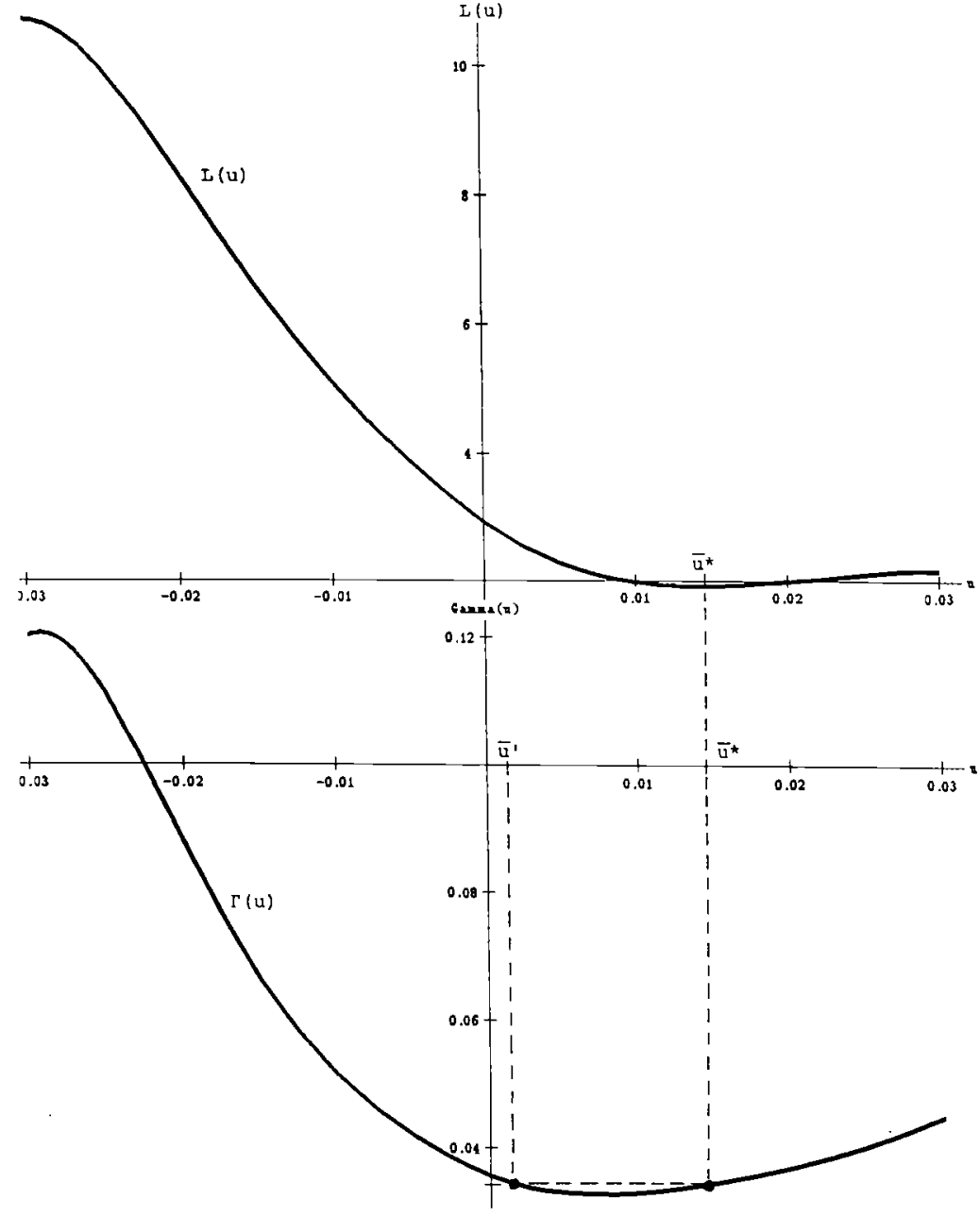

Figure 5: Multiple equilibria with $\lambda=0.9, k=0.015$ 


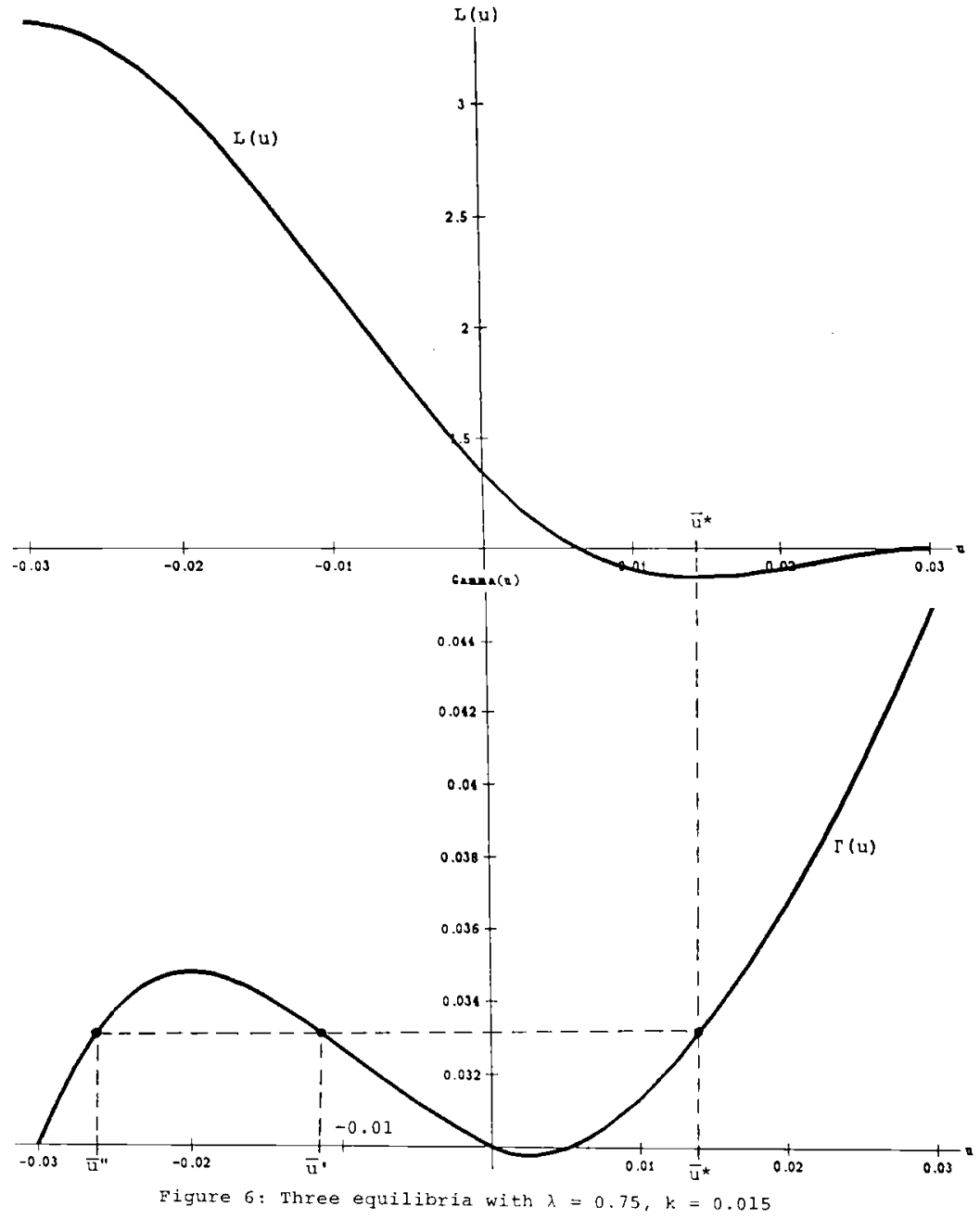


0.39 percent, and a 0.133 chance of devaluation. This equilibrium dominates the fixed-rate solution, since $\mathrm{L}(.03)=1$.

Imposing the fixed devaluation cost $\kappa=\Gamma\left(\vec{u}^{*}\right)$ might not suffice to replicate this relatively attractive equilibrium. The figure's lower panel indicates two very different additional equilibria, associated with the boundaries $\bar{u}^{\prime}=-0.0123$ and $\bar{u}^{\prime \prime}=$ -0.0256 , and with the expected depreciation rates $\varphi^{\prime}=3.0$ percent and $\varphi^{\prime \prime}=4.4$ percent, respectively. (Figure $2 \mathrm{a}$ used the parameters of this example to plot expected depreciation.) The implied losses are $L\left(\bar{u}^{\prime}\right)=2.402, L\left(\bar{u}^{\prime \prime}\right)=3.291$, both much higher than that under a pure fixed-rate regime. Indeed, the low-threshold equilibrium is little better than unfettered discretion, where inflation runs at 4.5 percent per period and $L(-.03)-3.359$. In this last case, the market forecasts that the authority has only a minimal chance of defending the fixed exchange rate; these expectations lead to nominal wages that are so high (compared with the existing exchange rate) that devaluation nearly always is the outcome.

Figure 7 summarizes the effects of different propensities to accommodate by showing how $\Gamma(u)$ varies with $\lambda$ (for $k=0.015$ ). ${ }^{18}$

The examples show that attempts to delegate to an agent a rule with an escape clause can have a wide range of outcomes. Allowing for additional economic disturbances, for complicated distributions of these shocks, for revaluation as well as devaluation options, and for the interaction of several official

\footnotetext{
${ }^{18}$ Notice that $\Gamma^{\prime}(-\mu)=\delta^{\prime}(-\mu)+1=1$, and that $\delta(-\mu)=\lambda k /(1-\lambda)$ rises sharply with $\lambda$. Figure 2 shows that $\delta(u)$ initially falls slowly (or rises) as $\bar{u}$ is increased from $-\mu$, then falls at an increasing rate, and finally falls slowly to 0 . Figure 7 results.
} 


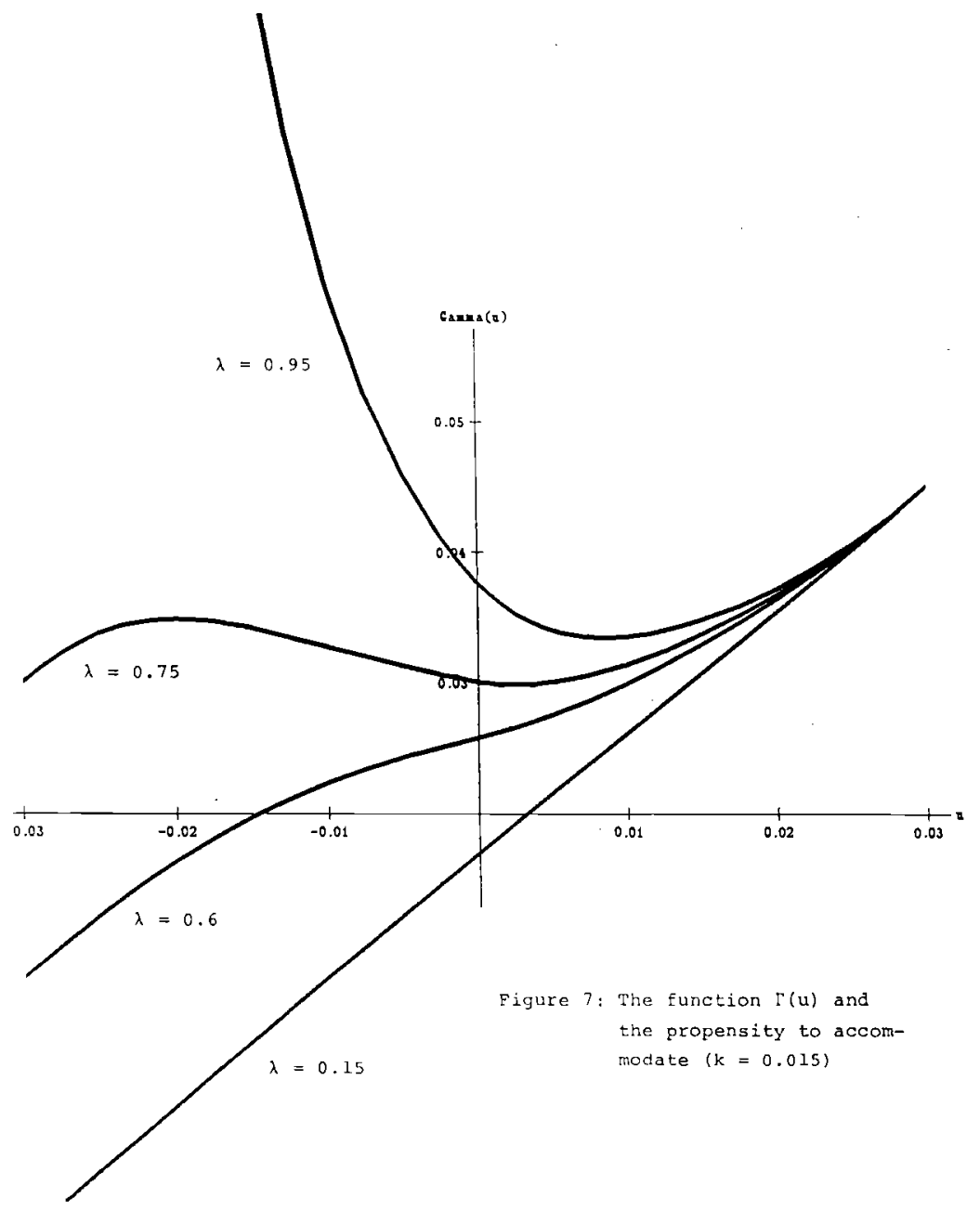


decision makers within frameworks like the EMS, can only multiply the possibilities.

In addition, there has been no formal analysis of the most obvious practical obstacle to implementing schemes like those in section II: uncertainty over the structure of the economy, which makes it difficult to judge accurately the appropriate personal costs to impose on policymakers. Acknowledging that such uncertainty is pervasive only makes escape options look worse.

In judging the relevance even of the examples given above, however, it is useful to have a rough idea of how accommodative policymakers are likely to be in practice. To this end, imagine a policymaker in a nonstochastic environment who faces no time-inconsistency problem $(k=0)$ and has an annual discount factor of $\beta=0.90$ (making him rather farsighted).

How many percentage point-years of unemployment would he be willing to tolerate to reduce inflation permanently from 1 to 0 percent per year? A dedicated inflation fighter might be willing to suffer three years of 2 percent unemployment (above the natural rate) for this reduction. The loss function (3) then implies $\theta=$ 1.08 ; and if $\alpha=3$, the policymaker is revealed to have a fairly high $\lambda$ of $3 /(3+1.08)=0.735\left[\right.$ recall (4)]. ${ }^{19}$ Even governments

\footnotetext{
${ }^{19}$ Observed policy outcomes might reflect heavier discounting of the future by politicians (lower values of $\beta$ ), in which case $\theta$ would have to be higher to explain what we see. In one version of the underlying model that generates equation (2), $\sqrt{\alpha}$ can be identified with the reciprocal of capital's income share in GNP. This would imply an estimate of $\alpha$ around 9 , which seems unrealistically large; but supposing $\alpha-3$ is reasonable, at least for small deviations from the natural rate. On the other hand, if a significant time-inconsistency problem is present, the behavior described reveals different preferences: with $k=0.01$, recalculation leads to $\theta=2.96, \lambda=0.503$.
} 
that seem relatively inflation-averse may face problems in trying to implement adjustable fixed exchange rates.

\section{v. Conclusion}

Simple policy rules can often be amended to include welfare-enhancing escape clauses, which allow the exercise of discretion in well-defined circumstances. But even these amended rules are inherently time inconsistent. To implement them in a discretionary regime, society must confront policymakers with personal (perhaps political) costs of overriding rules.

Unfortunately, imposing the appropriate cost on the policymaker is necessary, but not sufficient, for reaching a socially preferred equilibrium. Market expectations can be self-fulfilling, leading in general to any number of equilibria, most of which are dominated by the original simple rule.

This paper illustrated these propositions by analyzing a fixed exchange rate system amended to include a devaluation option. Numerical examples suggested that a unique equilibrium may exist when a fairly non-accommodative policymaker faces a small time-inconsistency problem. In less favorable circumstances, however, a multiplicity problem will plague the attempt to delegate an optimal escape-clause rule. The problem is amplified in practice by the uncertainty society faces over the accurate measurement of both policymaker costs and their influence on policy actions. 


\section{References}

Barro, Robert J., and David B. Gordon. "A Positive Theory of Monetary Policy in a Natural Rate Model." Journal of Political Economy 91 (1983), 589-610.

Calvo, Guillermo A. "Servicing the Public Debt: The Role of Expectations." American Economic Review 78 (1988), 1411-28.

Cukierman, Alex. "Discretion, Precommitments and the Prospects for a European Central Bank - Fixed Parities versus a Commonly Managed Currency." Manuscript, Tel-Aviv University, 1990.

Flood, Robert P., and Peter Isard. "Monetary Policy Strategies." International Monetary Fund Staff Papers 36 (1989), 612-32. - Monetary Policy Strategies - A Correction: Reply to Lohmann." International Monetaxy Fund Staff Papers 37 (1990), 446-48.

International Monetary Fund. World Economic Outlook. Washington, D.C.: International Monetary Fund, May 1990.

Kydland, Finn E., and Edward C. Prescott. "Rules Rather Than Discretion: The Inconsistency of Optimal Plans." Journal of Political Economy 85, 473-92. 
Lewis, Karen K. "On Occasional Monetary Policy Coordinations that Fix the Exchange Rate." Journal of International Economics 26 (1989), 139-55.

Lohmann, Suzanne. "Monetary Policy Strategies - A Correction: Comment on Flood and Isard." International Monetary Fund Staff Papers 37 (1990), 440-45.

Obstfeld, Maurice. "Floating Exchange Rates: Experience and Prospects." Brookings Papers on Economics Activity, 2:1985, $369-450$.

Persson, Torsten, and Guido Tabellini. Macroeconomic Policy, Credibility and Politics. Fundamentals of Pure and Applied Economics 38. Chur, Switzerland: Harwood Academic Publishers, 1990.

Rogoff, Kenneth. "The Optimal Degree of Commitment to an Intermediate Monetary Target." Quarterly Journal of Economics 100 (1985), $1169-90$. 